\title{
Erratum to: Comparative Study on H20 Steel Billets: Additive Manufacturing vs. Powder Metallurgy
}

\author{
S. Nasar ${ }^{a}$, L. J. Baruch ${ }^{b}$, S. J. Vijayc , C. K. Srinivas ${ }^{a}$, J. Jose ${ }^{c}$, and V. V. Popov ${ }^{d, *}$ \\ ${ }^{a}$ Madanapalle Institute of Technology and Science, Andhra Pradesh, India \\ ${ }^{b}$ MVJ College of Engineering, Bangaluru, Karnataka, India \\ ${ }^{c}$ Karunya Institute of Technology and Sciences, Coimbatore, Tamil Nadu, India \\ ${ }^{d}$ Israel Institute of Metals, Technion's R\&D Foundation, Haifa, 3200003 Israel \\ *e-mail:vvp@technion.ac.il \\ Received June 5, 2020; revised August 24, 2020; accepted October 7, 2020
}

DOI: $10.1134 / \mathrm{S} 0031918 \mathrm{X} 21880025$

The article "Comparative Study on H20 Steel Billets: Additive Manufacturing vs. Powder Metallurgy", written by S. Nasar, L. J. Baruch, S. J. Vijay, C. K. Srinivas, J. Jose, and V. V. Popov, was originally published electronically in Springer-Link on 01 may 2021 without Open Access. After publication in volume 122 , issue 5 , pages $515-526$ the authors decided to make the article an Open Access publication. Therefore, the copyright of the article has been changed to (C) The Author(s) 2021 and the article is forthwith distributed under the terms of a Creative
Commons Attribution 4.0 International License (http://creativecommons.org/licenses/by/4.0/, CC BY), which permits use, duplication, adaptation, distribution and reproduction of a work in any medium or format, as long as you cite the original author(s) and publication source, provide a link to the Creative Commons license, and indicate if changes were made.

The original article can be found online at https://doi.org/10.1134/S0031918X21050100 